\title{
Steady state electrospinning of uniform polyethersulfone nanofibers using a non-heated solvent mixture
}

\author{
Godfred Darko $^{1,2}$ (1) Annelies Goethals ${ }^{3} \cdot$ Nelson Torto $^{2,4} \cdot$ Karen De Clerck $^{3}$
}

Received: 27 May 2015/ Accepted: 28 September 2015/Published online: 6 October 2015

(C) The Author(s) 2015. This article is published with open access at Springerlink.com

\begin{abstract}
Electrospinning is the most promising method for the large-scale production of nanofiber membranes. Multi-nozzle systems have already proven to be successful in producing polyamide nanofiber membranes suitable for water filtration. In this contribution, conditions for steady state electrospinning of polyethersulphone were investigated. Steady state electrospinning of PES was only possible for a limited number of electrospinning parameter combinations. Only a polymer concentration of 25 and $26 \mathrm{wt} \%$ resulted in defect-free nanofiber membranes. The solvent ratio of DMF:NMP can be varied from 95:5 (v:v\%) to $85: 15(\mathrm{v}: \mathrm{v} \%)$ to generate uniform nanofibers with average diameters varying from 300 to $730 \mathrm{~nm}$ all with relatively narrow standard deviation as low as $20 \%$. These results, thus, allow for a well-chosen set of electrospinning parameters for scaling up electrospinning of polyethersulphone nanofiber membranes.
\end{abstract}

Keywords Electrospinning - Uniform nanofibers · Polyethersulfone $\cdot$ Steady state

Godfred Darko

gdarko.sci@knust.edu.gh

1 Department of Chemistry, Kwame Nkrumah University of Science and Technology, Kumasi, Ghana

2 Department of Chemistry, Rhodes University, Grahamstown 6140, South Africa

3 Department of Textiles, Ghent University, Technologiepark 907, 9052 Ghent, Belgium

4 Botswana Institute for Technology and Innovation, Gaborone, Botswana

\section{Introduction}

Electrospun polymer nanofibers have very small diameters, which create specific and unique characteristics such as a high specific surface, a small pore size and a high porosity. Due to these properties, electrospun polymer nanofibers can be used in a broad range of applications, such as composites, scaffolds, medical applications and filter media (Ahmed et al. 2015). Electrospinning is the most cost-effective method for large-scale production of nanofiber membranes (Greiner and Wendorff 2007; Bjorge et al. 2009; Daels et al. 2010). The electrospinning process makes use of an electric field that is applied across a polymer solution and a collector plate. As the solution jet travels, it is bent by the electric forces while the solvent evaporates (Hu et al. 2014; Sun et al. 2015). This mechanism leads to the formation of fibers which are attracted to the grounded or charged collector plate.

A single nozzle electrospinning setup using a flat collector has been successfully scaled up to a multi-nozzle system capable of producing large volumes of nanofiber membranes (Kim et al. 2006; Varesano et al. 2009; Daels et al. 2011). Steady state electrospinning is the key to a successful scale up of the electrospinning process (Spivak et al. 2000; De Vrieze et al. 2011; De Schoenmaker et al. 2012) and as a first step the steady state conditions on a single nozzle setup should be studied. Steady state electrospinning requires that all polymer in the solution pumped into the electric field is transformed into nanofibers. This results in highly reproducible nanofiber structures without any defects such as drops and beads. The Taylor cone which is formed during electrospinning should be stable throughout the electrospinning period and the deposition region should be well defined. These requirements are crucial to obtain large membranes with 
nanofibers of uniform diameters. If the deposition region varies during electrospinning, the thickness of the nanofibers will not be uniform, which will result in different properties within one nanofiber membrane.

The steady state condition is thus stricter than the common conditions for stable electrospinning which are often described in literature (Fong et al. 1999; Zuo et al. 2005; Carroll and Joo 2009). To achieve steady state electrospinning, it is crucial to determine a suitable solvent system (De Vrieze et al. 2010; Van der Schueren et al. 2011). By studying steady state electrospinning of polyamides, it was possible to produce large uniform membranes that were further studied for use in water filtration (Bjorge et al. 2009; Daels et al. 2010, 2011). The same approach can be used to scale up the electrospinning of other polymers.

This paper investigates the conditions for achieving steady states for electrospinning of polyethersulphone (PES). This polymer offers excellent toughness, thermal stability and outstanding hydrolytic resistance. Unlike the polyamide nanofiber membranes, PES nanofibers' membranes can be sterilized using either steam or autoclaving. For this reason, PES is often used as a membrane material in the biotechnological and pharmaceutical industries $(\mathrm{Xu}$ and Alsalhy Qusay 2004; Rahimpour et al. 2010). Electrospinning of PES is mostly performed with single solvents such as dimethylformamide (DMF) and dimethylacetamide (DMAc) (Lin et al. 2008; Babaeijandaghi et al. 2010; Homaeigohar et al. 2010), although solvent mixtures such as DMF:toluene (Ma et al. 2009) or DMF:NMP (Yoon et al. 2009; Tang et al. 2009; Bui et al. 2011) have also been attempted. The use of heated mixtures such as DMF:NMP solution is mainly aimed at wet spinning of PES nanofibers onto a carrier. However, little attention is given to the stability of the electrospinning process itself and no information is provided about the duration and reproducibility of the experiments.

This study focusses on steady state electrospinning of non-heated PES solutions prepared with DMF:NMP solvent mixtures which remain stable at room temperature making them suitable for use in multi-nozzle systems. The effect of different electrospinning parameters on the steady state was investigated and the formed nanofibers characterized. Currently, the literature describes electrospun PES fiber diameters with standard deviations ranging from $35 \%$ to more than $50 \%$ (Lin et al. 2008; Ma et al. 2009; Tang et al. 2009; Homaeigohar et al. 2010; Bui et al. 2011). We also investigated whether the PES electrospun under steady state conditions gives more uniform nanofibers' diameters. This study contributes to the scaling-up of the electrospinning process to produce industrially usable nanofibers for different applications such as water filtration.

\section{Materials and methods}

All solvents were of analytical grade. Dimethylformamide (DMF), dimethylacetamide (DMAc) and $\mathrm{N}$-methylpyrrolidone (NMP) were purchased from Sigma-Aldrich. Properties of these solvents are summarized in Table 1.

Gafone 3100P polyethersulphone (PES) was supplied by Solvay (Brussels, Belgium). Gel permeation chromatography was used to determine the molecular weight: $M_{n}=17 \times 10^{3}, M_{w}=75 \times 10^{3}$ and $M_{w} / M_{n}=4.4$. The PES solutions were prepared by dissolving calculated and accurately weighed mass of PES powder in various solvent systems. The solutions were stirred at room temperature for a minimum of $3 \mathrm{~h}$ to ensure complete dissolution. Before electrospinning, viscosity of the solutions was measured using a Brookfield viscometer LVDV-II and the conductivity was measured with a Radiometer Analytical CDM210 conductivity meter.

During the electrospinning process, the polymer solution was pumped from a $20 \mathrm{~mL}$ syringe into a $15.24 \mathrm{~cm}$ long needle having an inner diameter of $1.024 \mathrm{~mm}$ (Fig. 1). A KD Scientific Syringe Pump Series 100 regulated the flow rate of the solution. The voltage was adjusted using a Glassman High Voltage Series EH source. The process parameters that were varied during electrospinning are the flow rate $(0-2 \mathrm{~mL} / \mathrm{h})$, the tip to collector distance (TCD) $(6-18 \mathrm{~cm})$ and the applied voltage $(0-30 \mathrm{kV})$. To minimize the effect of the ambient conditions (Medeiros et al. 2008; De Vrieze et al. 2008), all experiments were performed in a fume hood at room temperature $\left(22 \pm 2{ }^{\circ} \mathrm{C}\right)$ and at a relative humidity of $45 \pm 5 \mathrm{RH} \%$, monitored by a Vaisala humidity probe. The morphology of the electrospun structures was examined using an FEI QUANTA $200 \mathrm{~F}$ Scanning Electron Microscope (SEM). Prior to the SEM measurements, the sample was coated with gold using a sputter coater (Balzers Union SCD 030). The average fiber diameter was estimated by measuring the diameters of fifty fibers using the Cell ${ }^{\mathrm{D}}$ software (Olympus).

The steady state was checked by observing the stability of the Taylor cone for $30 \mathrm{~min}$ and verified by the absence of droplets and/or beads on SEM images. The steady state conditions were presented in a steady state table in which the solution parameters such as solvent ratio and polymer concentration were varied on the $x$ and $y$ axis, respectively. Once electrospinning was achieved, all other parameters were kept constant except the TCD, which was varied to establish steady state. This allowed for the demarcation of a steady state region within the steady state table presenting the possible combinations of solvent ratio and polymer concentration for which a steady state is possible. This methodology has been used previously to verify the steady states for electrospinning different types of polyamides (De 
Table 1 Properties of the solvents DMF, DMAc and NMP

\begin{tabular}{llll}
\hline Property & DMF & DMAc & NMP \\
\hline Vapor pressure $(\mathrm{kPa})$ & 0.300 & 0.300 & 0.066 \\
Dielectric constant & 36.7 & 37.8 & 32.2 \\
Surface tension $\left(\mathrm{N} \mathrm{m}^{-1}\right)$ & 37.10 & 32.34 & 40.70 \\
Boiling point $\left({ }^{\circ} \mathrm{C}\right)$ & 153 & 165 & 202 \\
Density $\left(\mathrm{g} \mathrm{cm}^{-3}\right)$ & 0.944 & 0.937 & 1.028 \\
Viscosity $(\mathrm{mPa} \mathrm{s})$ & 0.92 & 1.96 & 1.65 \\
\hline
\end{tabular}

Fig. 1 Scheme of electrospinning setup with indication of the process parameters

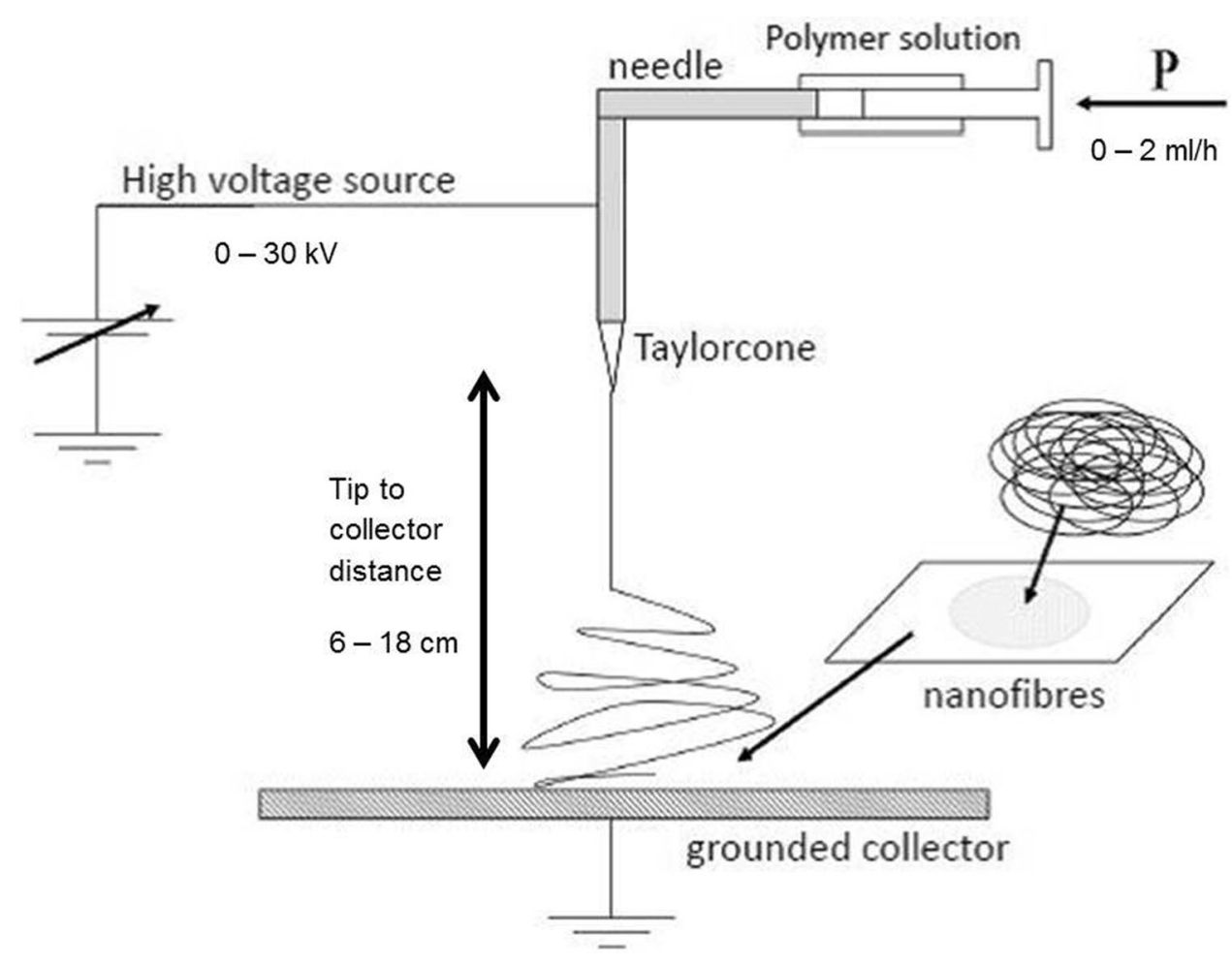

Vrieze et al. 2008, 2010, 2011; De Schoenmaker et al. 2012) and polycaprolactones (Van der Schueren et al. 2011).

\section{Results and discussion}

\section{Solvent study}

Prior to electrospinning, characteristics of the PES solutions in different solvents were studied. Based on the literature, pure DMF, DMAc and NMP were used as solvents. Initial screening showed that PES solutions prepared with pure DMF, NMP or DMAc are not suitable for steady state electrospinning. Even though nanofibers can, somehow, be electrospun from the individual solvents, the Taylor does not remain stable resulting in dripping and bead formation. This is because the individual solvents do not require rheological properties to hold the polymer solution long enough in the electric field to electrospin uniformly. Dissolution of PES in pure DMAc leads to the formation of viscous gel upon standing while solution formed with pure NMP evaporates rapidly at the nozzle tip during electrospinning. PES has a low miscibility in pure DMF and also requires relatively high environmental humidity to electropin (Fashandi and Karimi 2014). For other polymers, such as cellulose (Ahn et al. 2012), polyamides (De Vrieze et al. 2010, 2011; De Schoenmaker et al. 2012) and polycaprolactone (Van der Schueren et al. 2011), stable electrospinning was accomplished using binary solvents. The use of binary solvent systems resulted in a larger window for steady state electrospinning. 
The initial screening showed that addition of small amounts of NMP to the mixture of PES and DMF increases the ability to electrospin. The surface tension and boiling point of DMF are lower than those of NMP, while the vapor pressure of DMF is higher than that of NMP. Therefore, blending DMF with NMP reduces the rate of solvent evaporation which is one of the parameters that largely affects electrospinning (Tripatanasuwan et al. 2007). Thus, electrospinning PES solutions in DMF:NMP solvent mixtures at room temperature could potentially lead to a steady state electrospinning.

During the preliminary tests, several solutions were heated while stirring to achieve homogeneity. However, their viscosities increased as they cooled to room temperature by rendering them too viscous to electrospin. It is necessary for electrospinning solutions to maintain stable properties for scaling up purposes. An increase in viscosity during electrospinning could affect steady state electrospinning or could lead to clogging of the needle and is, therefore, not desired. All solutions were, therefore, prepared at room temperature and left stirring for $3 \mathrm{~h}$ to determine whether the solutions remain unchanged for longer periods of time.

Viscosity and conductivity of the electrospinning solution are solution properties that have a major influence on electrospinning. Table 2 shows the viscosity and conductivity of the PES solutions. Viscosity of polymer solutions increases with increasing PES concentration. Up to $25 \mathrm{wt} \%$ PES, the viscosity increases gradually. There is a remarkably sharp increase in viscosity when the polymer concentration was increased further. Viscosity of the solution also increases with increasing fraction of NMP. Density and viscosity of NMP are higher than those of DMF. Therefore, increasing the proportion of NMP increases the viscosity of the solution even at a constant polymer concentration. This trend is more explicit for high polymer concentrations. Generally, conductivity of the electrospinning solution decreases with increasing PES concentration. This is not unexpected since the polymer itself is not charged. Conductivity of the polymer solution is mainly determined by those of the solvents in the solutions.
Table 3 summarizes the behavior of the polymer solutions, all made at room temperature, that are of interest for electrospinning. The polymer does not dissolve at concentrations higher than $28 \mathrm{wt} \%$, regardless of the solvent composition (black region). Full dissolution always occurs when the polymer concentration is less than $24 \mathrm{wt} \%$. Concentrations and solvent combinations indicated in the gray region form highly viscous gels after $3 \mathrm{~h}$. The rate and extent of gel formation are dependent on the polymer concentration and the composition of the solvent system. Lower proportions of NMP lead to a greater extent and a faster rate of gel formation. The formed gel is too viscous for electrospinning. Heating the gel reduces the viscosity. However, viscosity increases again when the solution cools which results in clogging of the electrospinning nozzle. The white region indicates the PES solutions that dissolve completely without gel formation and is, therefore, the operational region to be studied in more detail for steady state electrospinning.

Table 3: Solubility characteristics of polyethersulfone in various composition ratios of DMF and NMP at room temperature. Black: not dissolved; gray: dissolved, gel formation; white: dissolved, no gel formation.

\section{Steady state conditions}

The PES solutions (within the operational region) were electrospun using the setup as shown in Fig. 1. Steady state electrospinning conditions were explored by varying the process parameters for each solution. The PES concentration was varied from 15 up to $27 \mathrm{wt} \%$ and the fraction of NMP from 0 to $25 \mathrm{v} \%$. Concentrations lower than $15 \mathrm{wt} \%$ were not viscous enough to electrospin. A minimum mass and viscosity are required for electrospinning to start (Huang et al. 2003).

Steady state conditions were first visually assessed by monitoring the stability of the Taylor cone and the deposition region of the nanofibers. The steady state conditions are observed for PES solutions from 15 up to $20 \mathrm{wt} \%$. SEM images (Fig. 2a), however, showed that uniform droplets were formed due to too low viscosity and fluid jet break up.

Table 2 The solution characteristics: viscosity and conductivity

\begin{tabular}{|c|c|c|c|c|c|c|c|c|c|c|}
\hline \multirow[t]{3}{*}{ PES concentration (wt\%) } & \multicolumn{5}{|c|}{ Viscosity $\left(\mathrm{Ns} / \mathrm{m}^{2}\right)$} & \multicolumn{5}{|c|}{ Conductivity (mS/cm) } \\
\hline & \multicolumn{5}{|c|}{ Fraction of NMP in DMF:NMP solution (v\%) } & \multicolumn{5}{|c|}{ Fraction of NMP in DMF:NMP solution (v\%) } \\
\hline & 0 & 5 & 10 & 15 & 20 & 0 & 5 & 10 & 15 & 20 \\
\hline 22 & 1346 & 1412 & 1431 & 1435 & 1453 & 0.012 & 0.012 & 0.013 & 0.015 & 0.015 \\
\hline 24 & 1486 & 1542 & 1559 & 1576 & 1583 & 0.011 & 0.013 & 0.013 & 0.013 & 0.013 \\
\hline 25 & 1552 & 1613 & 1623 & 1638 & 1648 & 0.010 & 0.010 & 0.010 & 0.010 & 0.010 \\
\hline 26 & 2018 & 2080 & 3635 & 3848 & - & 0.006 & 0.009 & 0.009 & 0.009 & 0.009 \\
\hline
\end{tabular}

- The measurement was out of range of the instrument used 
Table 3 Electrospinnability window

\begin{tabular}{ccccccc}
\hline \multirow{2}{*}{ wt $\%$ PES } & \multicolumn{5}{c}{ DMF:NMP solvent ratio (v\%) } \\
\cline { 2 - 6 } & $100: 0$ & $95: 5$ & $90: 10$ & $85: 15$ & $80: 20$ & $75: 25$ \\
\hline 24 & & 5 & & & \\
\hline 25 & & & & & & \\
\hline 26 & & & & & & \\
\hline 27 & & & & & \\
\hline 28 & & & & & \\
\hline
\end{tabular}

As such electrosprayed beads were obtained. From 20 to 24 wt $\%$ PES solution, the Taylor cone was often interrupted by dripping regardless of the solvent ratio used. By increasing the applied voltage, the dripping could be eliminated but the Taylor cone was no longer stable and the deposition area no longer well defined. Thus, not all the steady state conditions can be fulfilled at the same time. Bead formation depends on the viscosity and surface tension of the solution (Huang et al. 2003). Low viscosity and high surface tension favor bead formation. SEM images (Fig. 2b) show that the formed nanofibers contain less droplets, but still contain beads. Therefore, PES concentrations up to $24 \mathrm{wt} \%$ could not be electrospun under steady state conditions.

Solvent ratios play a leading role in steady state electrospinning of PES solutions of more than $25 \mathrm{wt} \%$. Solutions of $25 \mathrm{wt} \%$ polymer in pure DMF exhibit solidification at the tip of the needle; therefore, steady state conditions cannot be achieved. A stable Taylor cone and deposition area are found for $25 \mathrm{wt} \%$ solutions with a solvent ratio ranging from 5 to $15 \mathrm{v} \%$ NMP at a TCD of $13 \mathrm{~cm}$, a flow rate of $1 \mathrm{~mL} / \mathrm{h}$ and an applied voltage of $10 \mathrm{kV}$. Varying the process parameters results in an unstable Taylor cone or dripping from the needle. A thorough examination of the SEM images (Fig. 3a) reveals that the $25 \mathrm{wt} \%$ PES solutions with 5 and $10 \mathrm{v} \%$ NMP give defect-free nanofibers. However, in $15 \mathrm{v} \%$ NMP solutions, no steady state is achieved, resulting in the formation of large beads in the nanofiber structure. When the volume fraction of NMP increases even more, it was no longer possible to electrospin the solutions because of the excess of less volatile NMP in the solution. This causes unwanted wet deposition of the nanofibers onto the collector resulting in the dissolution of the already formed nanofibers.

Similar observations were made for the $26 \mathrm{wt} \%$ PES solution. The $26 \mathrm{wt} \%, 5 \mathrm{v} \% \mathrm{NMP}$ is stable for a TCD of $13 \pm 2 \mathrm{~cm}$, a flow rate of $1 \mathrm{~mL} / \mathrm{h}$ and a constant applied voltage of $10 \mathrm{kV}$. With an increasing fraction of NMP, the range of TCD that results in steady state electrospinning narrows. For $26 \mathrm{wt} \%$ at $20 \mathrm{v} \%$ NMP, only a TCD of $13 \mathrm{~cm}$ is possible; any variation results in an unstable Taylor cone. SEM images (Fig. 3b) show that these solutions are completely without any defects and truly fulfill the steady state conditions. Increasing the fraction of NMP to $25 \mathrm{v} \%$ leads again to undesired wet deposition. The volume fraction of NMP is thus crucial in achieving steady state electrospinning. A minimal fraction of NMP is necessary to guarantee that the solution does not all evaporate at the tip of the needle, whereas an excess of NMP clearly results in wet deposition.

When the PES concentration is increased to $27 \mathrm{wt} \%$, solidification at the tip of the nozzle occurs regardless of
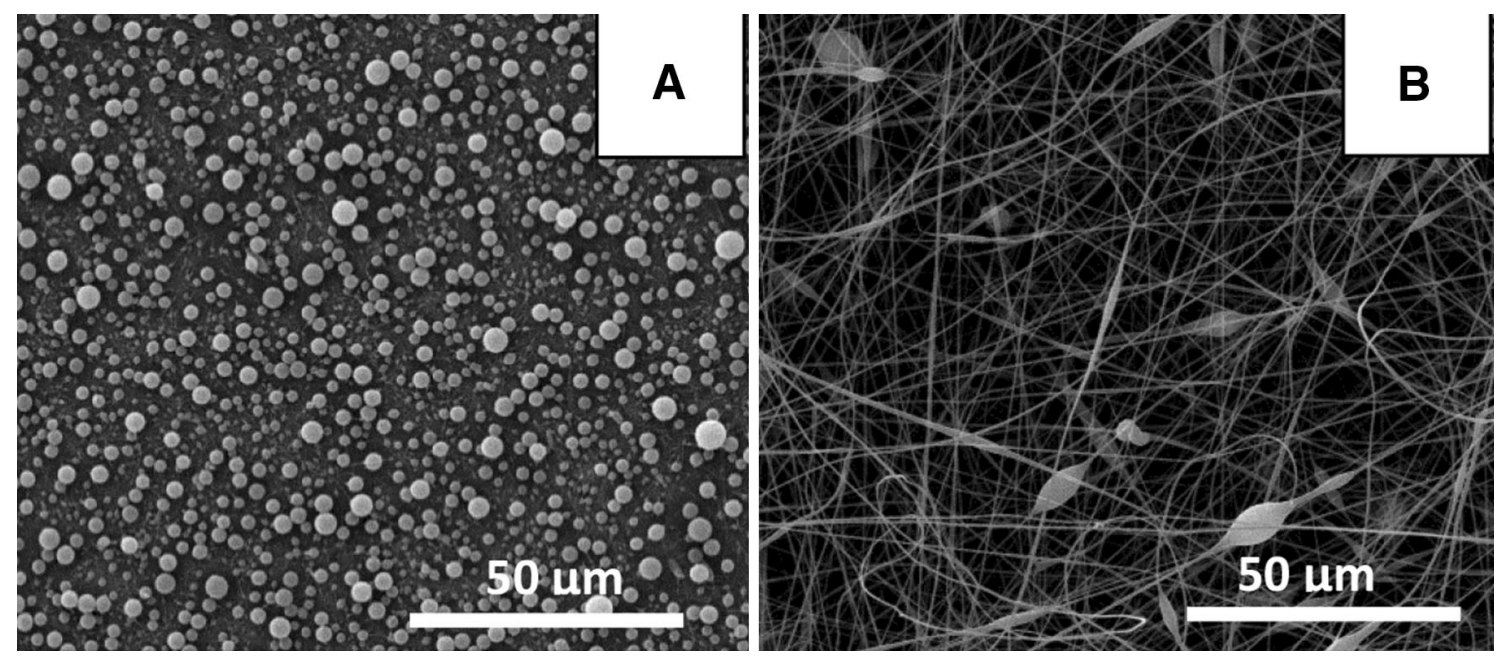

Fig. 2 SEM images of non-steady state electrospinning. a 15 wt $\%$ PES (production of droplets), 5 v\% NMP, b 24 wt $\%$ PES, 5 v\% NMP (production of beads) 


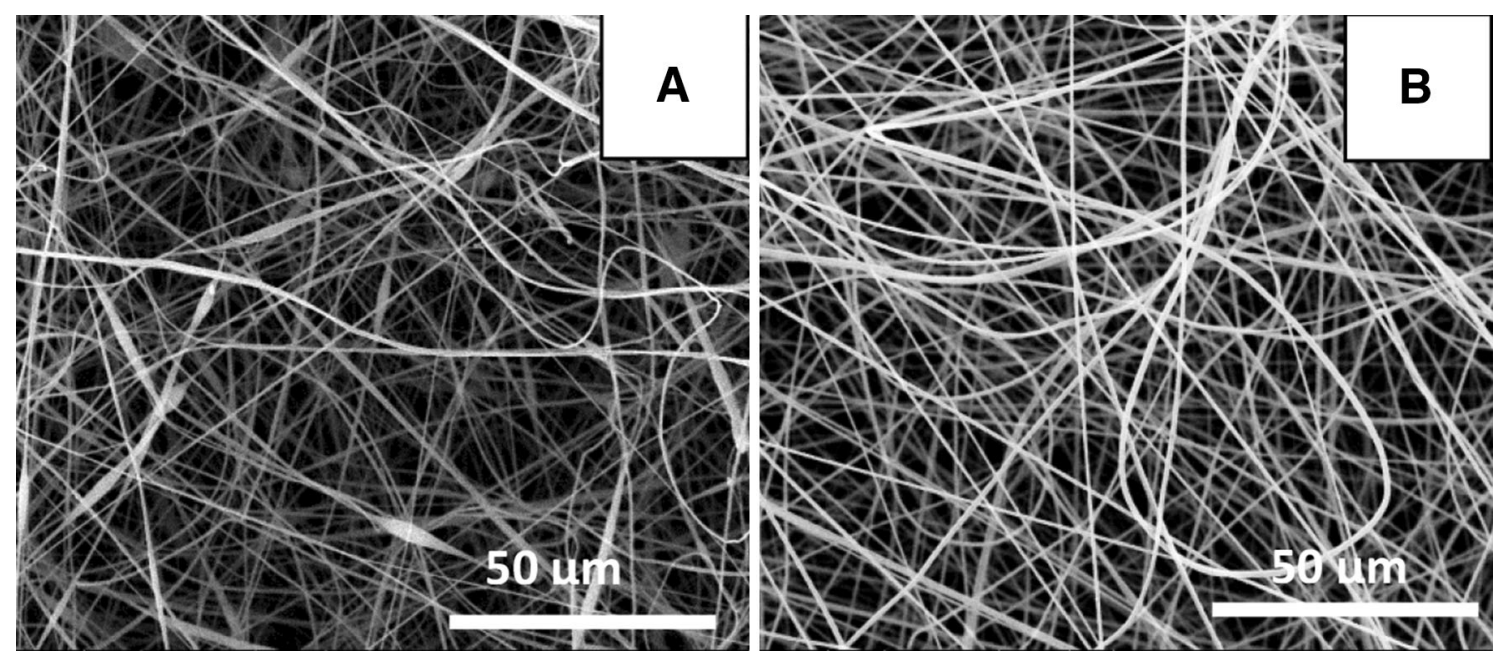

Fig. 3 SEM images of steady state electrospinning. a 25 wt $\%$ PES, 5 v\% NMP, b 26 wt $\%, 5$ v\% NMP

the amount of NMP. This is because the solution is too close to its solubility limits. During electrospinning, the solvent evaporates quickly, thus the concentration of the polymer increases while the jet follows its path towards the collector plate. Solution drying occurs at the tip of the needle; therefore, steady state electrospinning is not possible.

Table 4 summarizes the steady state behavior of the electrospinning of PES in DMF:NMP. The gray region indicates the solutions for which no process parameters leading to steady state electrospinning could be found. The black region indicates solutions which solidify close at the tip of the needle, thus electrospinning is not possible. Steady state electrospinning occurred only in the white region. It is important to conclude that the steady state region of PES is very limited, since both PES concentration and process parameters cannot be varied much without disrupting the steady state conditions. Yet, through the combination of DMF and NMP, it is possible to electrospin PES under steady state conditions without heating the solutions. This is an important breakthrough for scaling up to a multi-nozzle system and thus for potential future applications in water treatment.

Table 4: Steady state table for electrospinning of PES in DMF:NMP (applied voltage: $10 \mathrm{kV}$, flow rate: $1 \mathrm{~mL} / \mathrm{h}$, relative humidity $45 \pm 5 \% \mathrm{RH}$ ). TCD for steady state electrospinning is indicated in $\mathrm{cm}$. White region: steady state region; gray region: not suited for electrospinning; black region: drying at the tip of the needle.

\section{Study of the fiber morphology}

Figure 4 shows the average fiber diameters and standard deviations as a function of solvent ratio and polymer concentration. The black data points correspond to the solutions in the steady state region. The white data points are not part of the steady state region. Table 5 describes the average fiber diameter and the standard deviation expressed in percentage.

Similar to other polymers, the fiber diameter increases with increasing polymer concentration when the fraction of NMP is constant. It is important to note that a $1 \%$ increase in PES concentration results in a significant increase in fiber diameter. This is caused by the increase in viscosity which results in the stability of the jet to set in from a longer distance from the tip of the nozzle causing thicker fibers. Moreover, decrease in solvent fractions in the electrospinning solution causes the jets to solidify more quickly, thus resulting in a less stretched fiber (Sutasinpromprae et al. 2006; Jacobs et al. 2010). The 25 wt $\%$ PES in 85:15 v:v\% DMF:NMP solution is not part of the steady state region, because of beads and drops in the structure of the membrane formed. Since beads and drops take up a fair amount of polymer that cannot be used for the formation of
Table 4 Steady state electrospinnability window

\begin{tabular}{|c|c|c|c|c|c|c|}
\hline \multirow{2}{*}{$\mathrm{wt} \% \mathrm{PES}$} & \multicolumn{6}{|c|}{ Fraction of NMP in DMF:NMP solution (v\%) } \\
\hline & 0 & 5 & 10 & 15 & 20 & 25 \\
\hline 24 & & & & & & \\
\hline 25 & & $13 \pm 0 \mathrm{~cm}$ & $13 \pm 0 \mathrm{~cm}$ & & & \\
\hline 26 & & & $13 \pm 2 \mathrm{~cm}$ & $13 \pm 1 \mathrm{~cm}$ & $13 \pm 0 \mathrm{~cm}$ & \\
\hline 27 & & & & & & \\
\hline
\end{tabular}




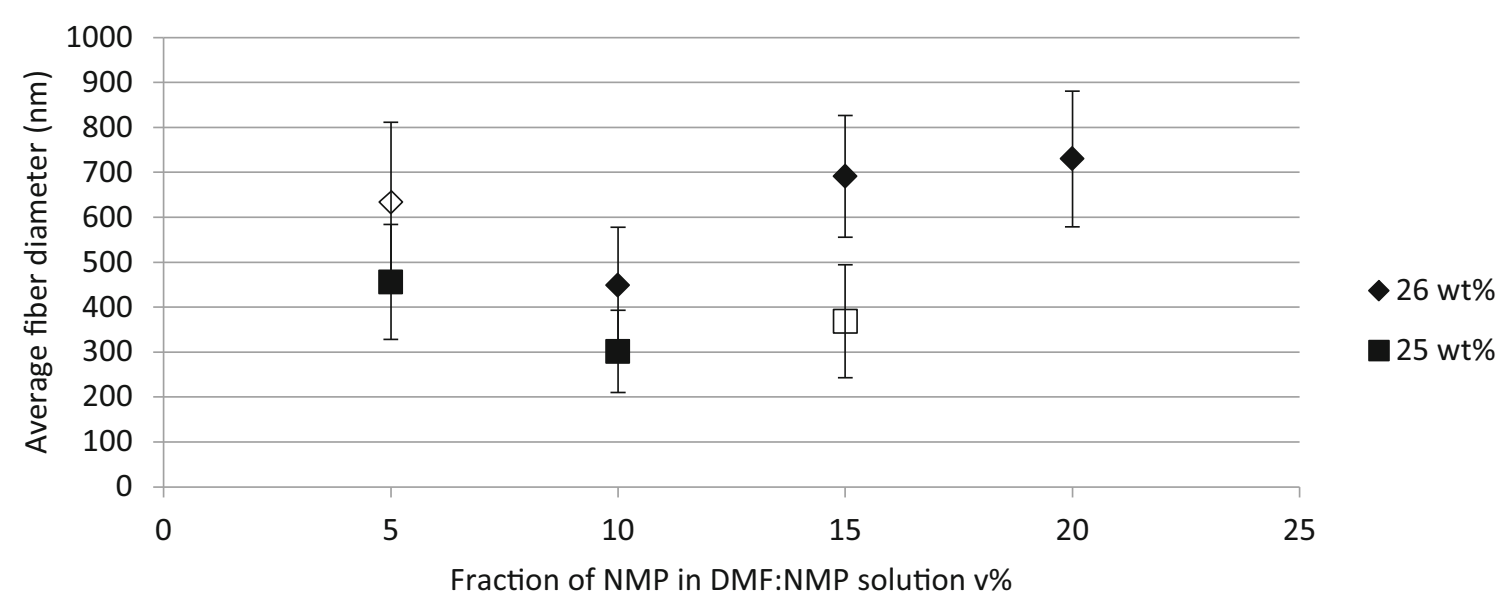

Fig. 4 Average fiber diameter as a function of PES concentration for 5 v\% NMP

Table 5 Average fiber diameter and \% deviation of 25 and 26 wt $\%$ PES for different fractions of NMP

\begin{tabular}{lllll}
\hline Fraction NMP & \multicolumn{2}{l}{$25 \mathrm{wt} \%$} & & \multicolumn{2}{l}{$26 \mathrm{wt} \%$} \\
\cline { 2 - 3 } & Diameter $(\mathrm{nm})$ & \% Deviation & Diameter (nm) & \% Deviation \\
\hline 5 & $456 \pm 128$ & 28 & $634 \pm 177$ & 28 \\
10 & $302 \pm 92$ & 30 & $449 \pm 129$ & 28 \\
15 & $369 \pm 126$ & 34 & $691 \pm 135$ & 20 \\
20 & & & $730 \pm 151$ & 20 \\
\hline
\end{tabular}

a uniform fiber, there are both thinner and thicker fibers present in the nanofiber structure, resulting in a larger standard deviation. All steady state electrospun nanofibers which are defect-free have lower standard deviations (as low as $20 \%$ ) and are, therefore, more uniform.

ANOVA and Tukey post hoc tests were performed at a $5 \%$ level of significance. All data were tested for homoscedasticity and normality of residuals. The results show that the fraction of NMP has a significant influence on the fiber diameter. The corresponding SEM images are shown in Fig. 5. Starting with $5 \mathrm{v} \% \mathrm{NMP}$, the average fiber diameter is $634 \mathrm{~nm}$ with a standard deviation of $28 \%$. By adding an additional $5 \mathrm{v} \%$ of NMP, the average fiber diameter becomes thinner. This is possibly caused by the slower evaporation rate of NMP allowing for longer stretching of the fiber, thus resulting in a thinner fiber. The standard deviation, however, remains at $28 \%$ because of the steady states attained. At $15 \mathrm{v} \% \mathrm{NMP}$, the average fiber diameter increases to $691 \pm 135 \mathrm{~nm}$. This confirms that a higher fraction of NMP does not only increase the evaporation time which would result in finer fibers, but also cause the viscosity to rise which leads to larger size fibers. A further increase in the fraction of NMP does not significantly affect the average fiber diameter. The uniformity of the nanofibers has increased since the standard deviation has lowered to $20 \%$. The similar trend in average fiber diameter is found in $25 \mathrm{wt} \%$ PES solutions (Fig. 5). Even with the very limited steady state area that was determined for non-heated PES solutions, a broad range of average fiber diameters can be achieved through accurate control of the electrospinning parameters. The average fiber diameter ranges from 300 to $730 \mathrm{~nm}$. Changes in the diameter will affect the pore structure of the nanofiber membranes (Song et al. 2015).

\section{Conclusion}

The steady state electrospinning of PES is possible with DMF:NMP as a solvent mixture even when the solutions are prepared and used at room temperature. This is in contrast to previous studies where only heated solutions were described and little attention was given to the scalability of PES electrospinning. At room temperature, some PES solutions are too viscous, leaving only a limited region of stable solutions for steady state electrospinning.

The characterization of the solution shows that the viscosity and conductivity are affected by both the polymer 

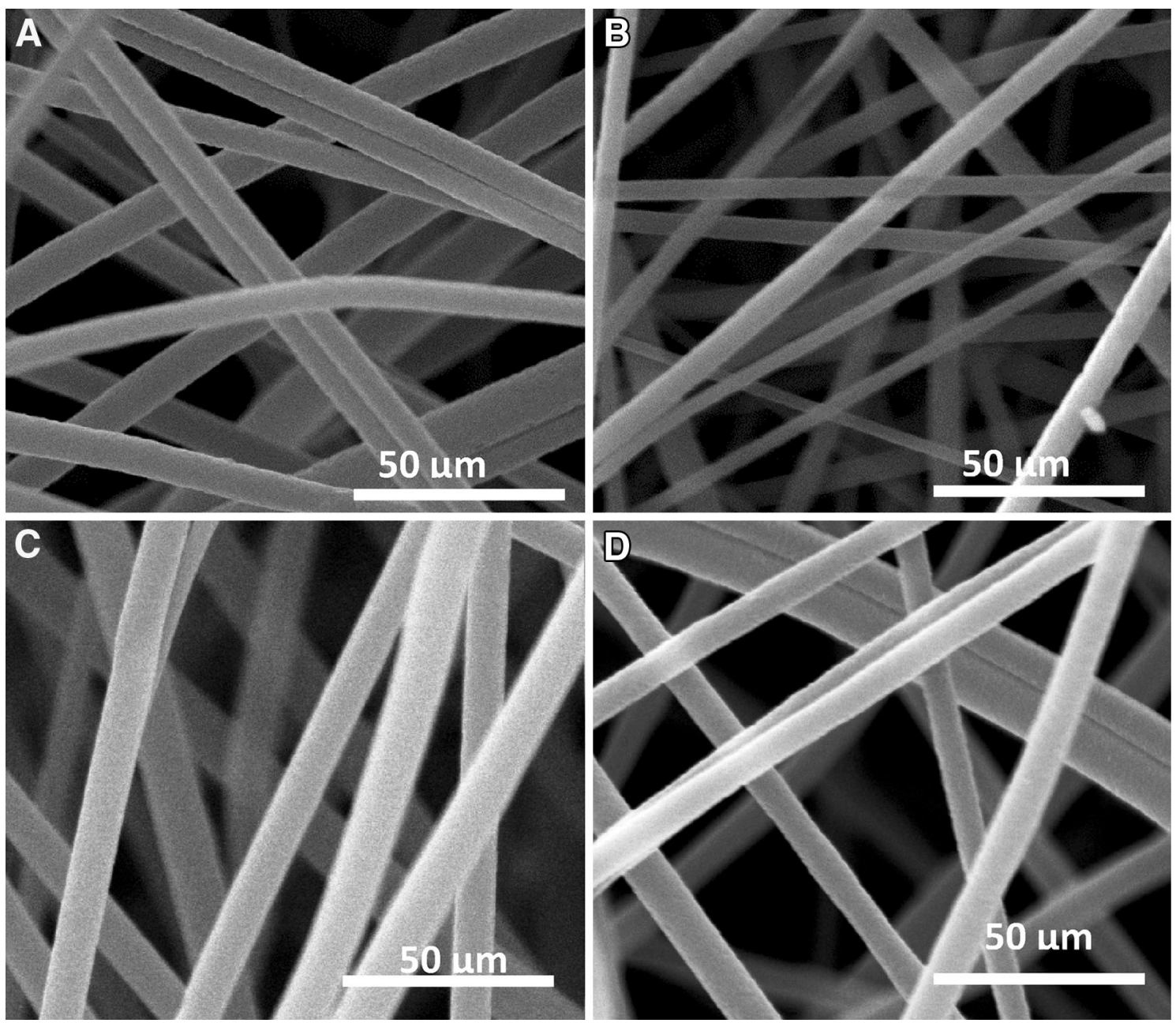

Fig. 5 SEM images of 26 wt \% PES. a 5 v\% NMP, b 10 v\% NMP, c 15 v\% NMP, d 20 v\% NMP

concentration and the solvent ratio. Moreover, the stability and reproducibility of the formed nanofibers are guaranteed by determining the steady state region. Steady state electrospinning under specific ambient conditions (temperature $20 \pm 2{ }^{\circ} \mathrm{C}$ and relative humidity $45 \pm 5 \% \mathrm{RH}$ ) is only possible for a very limited range of polymer concentrations and solvent ratios. Defect-free nanofiber membranes can be formed using 25 or $26 \mathrm{wt} \%$ PES solutions. The fraction of NMP in the solution can vary from 5 to $20 \mathrm{v} \%$ which also affects the fiber diameter. A fiber diameter range from 300 to $730 \mathrm{~nm}$ can be electrospun with a standard deviation as low as $20 \%$ which is less than other reported PES nanofibers (Tang et al. 2009; Homaeigohar et al. 2010). This study shows that the electrospinning of PES has the potential to be scaled up for the production of larger uniform nanofiber membranes that can be used in water filtration.

Acknowledgments Financial support from the Agency for Innovation by Science and Technology of Flanders (IWT) is gratefully acknowledged. The work was partially funded by the Department of Science and Technology (DST) and the National Research Foundation (NRF) of South Africa through DST/NRF South African Research Chairs Initiative for Professors of Medicinal Chemistry and Nanotechnology. The project was partially funded by FP7-PEOPLE2009-IRSES PROCOTEX.

Open Access This article is distributed under the terms of the Creative Commons Attribution 4.0 International License (http:// creativecommons.org/licenses/by/4.0/), which permits unrestricted use, distribution, and reproduction in any medium, provided you give appropriate credit to the original author(s) and the source, provide a link to the Creative Commons license, and indicate if changes were made.

\section{References}

Ahmed FE, Lalia BS, Hashaikeh R (2015) A review on electrospinning for membrane fabrication: challenges and applications. Desalination 356:15-30. doi:10.1016/j.desal.2014.09.033

Ahn Y, Hu D-H, Hong JH et al (2012) Effect of co-solvent on the spinnability and properties of electrospun cellulose nanofiber. 
Carbohydr Polym 89:340-345. doi:10.1016/j.carbpol.2012.03. 006

Babaeijandaghi F, Shabani I, Seyedjafari E et al (2010) Accelerated epidermal regeneration and improved dermal reconstruction achieved by polyethersulfone nanofibers. Tissue Eng Part A 16:3527-3536. doi:10.1089/ten.TEA.2009.0829

Bjorge D, Daels N, De Vrieze S et al (2009) Performance assessment of electrospun nanofibers for filter applications. Desalination 249:942-948. doi:10.1016/j.desal.2009.06.064

Bui N-N, Lind ML, Hoek EMV, McCutcheon JR (2011) Electrospun nanofiber supported thin film composite membranes for engineered osmosis. J Memb Sci 385-386:10-19. doi:10.1016/j. memsci.2011.08.002

Carroll CP, Joo YL (2009) Axisymmetric instabilities in electrospinning of highly conducting, viscoelastic polymer solutions. Phys Fluids 21:103101. doi:10.1063/1.3246024

Daels N, De Vrieze S, Decostere B et al (2010) The use of electrospun flat sheet nanofibre membranes in MBR applications. Desalination 257:170-176. doi:10.1016/j.desal.2010.02.027

Daels N, De Vrieze S, Sampers I et al (2011) Potential of a functionalised nanofibre microfiltration membrane as an antibacterial water filter. Desalination 275:285-290. doi:10.1016/j. desal.2011.03.012

De Schoenmaker B, Goethals A, Van der Schueren L et al (2012) Polyamide 6.9 nanofibres electrospun under steady state conditions from a solvent/non-solvent solution. J Mater Sci 47:4118-4126. doi:10.1007/s10853-012-6266-9

De Vrieze S, Van Camp T, Nelvig A et al (2008) The effect of temperature and humidity on electrospinning. J Mater Sci 44:1357-1362. doi:10.1007/s10853-008-3010-6

De Vrieze S, Westbroek P, Van Camp T, De Clerck K (2010) Solvent system for steady state electrospinning of polyamide 6.6. J Appl Polym Sci 115:837-842. doi:10.1002/app.30331

De Vrieze S, De Schoenmaker B, Ceylan Ö et al (2011) Morphologic study of steady state electrospun polyamide 6 nanofibres. J Appl Polym Sci 119:2984-2990. doi:10.1002/app.33036

Fashandi H, Karimi M (2014) Evidence for the impression of phase behavior of nonsolvent/solvent/polymer ternary system on morphology of polyethersulfone electrospun nanofibers. Fibers Polym 15:1375-1386. doi:10.1007/s12221-014-1375-5

Fong H, Chun I, Reneker D (1999) Beaded nanofibers formed during electrospinning. Polymer (Guildf) 40:4585-4592. doi:10.1016/ S0032-3861(99)00068-3

Greiner A, Wendorff JH (2007) Electrospinning: a fascinating method for the preparation of ultrathin fibers. Angew Chem Int Ed Engl 46:5670-5703. doi:10.1002/anie.200604646

Homaeigohar SS, Buhr K, Ebert K (2010) Polyethersulfone electrospun nanofibrous composite membrane for liquid filtration. J Memb Sci 365:68-77. doi:10.1016/j.memsci.2010.08.041

Hu X, Liu S, Zhou G et al (2014) Electrospinning of polymeric nanofibers for drug delivery applications. J Control Release 185:12-21. doi:10.1016/j.jconrel.2014.04.018

Huang Z, Zhang Y-Z, Kotaki M, Ramakrishna S (2003) A review on polymer nanofibers by electrospinning and their applications in nanocomposites. Compos Sci Technol 63:2223-2253. doi:10. 1016/S0266-3538(03)00178-7

Jacobs V, Anandjiwala RD, Maaza M (2010) The influence of electrospinning parameters on the structural morphology and diameter of electrospun nanofibers. J Appl Polym Sci 115:3130-3136. doi:10.1002/app.31396

Kim G, Cho Y-S, Kim WD (2006) Stability analysis for multi-jets electrospinning process modified with a cylindrical electrode.
Eur Polym J 42:2031-2038. doi:10.1016/j.eurpolymj.2006.01. 026

Lin Y, Yao Y, Yang X et al (2008) Preparation of poly(ether sulfone) nanofibers by gas-jet/electrospinning. J Appl Polym Sci 107:909-917. doi:10.1002/app.26445

Ma Z, Lan Z, Matsuura T, Ramakrishna S (2009) Electrospun polyethersulfone affinity membrane: membrane preparation and performance evaluation. J Chromatogr B Analyt Technol Biomed Life Sci 877:3686-3694. doi:10.1016/j.jchromb.2009. 09.019

Medeiros ES, Mattoso LHC, Offeman RD et al (2008) Effect of relative humidity on the morphology of electrospun polymer fibers. Can J Chem 86:590-599. doi:10.1139/v08-029

Rahimpour A, Madaeni SS, Mansourpanah Y (2010) Fabrication of polyethersulfone (PES) membranes with nano-porous surface using potassium perchlorate $(\mathrm{KClO} 4)$ as an additive in the casting solution. Desalination 258:79-86. doi:10.1016/j.desal. 2010.03.042

Song T, Chen Z, He H et al (2015) Orthogonal design study on factors affecting the diameter of perfluorinated sulfonic acid nanofibers during electrospinning. J Appl Polym Sci 132(14). doi:10.1002/ app. 41755

Spivak AF, Dzenis YA, Reneker DH (2000) Model of steady state jet in the electrospinning process. Mech Res Commun 27:37-42

Sun X, Liu Y, Shaw G et al (2015) Fundamental study of electrospun pyrene-polyethersulfone nanofibers using mixed solvents for sensitive and selective explosives detection in aqueous solution. ACS Appl Mater Interfaces 7:13189-13197. doi:10.1021/ acsami.5b03655

Sutasinpromprae J, Jitjaicham S, Nithitanakul M et al (2006) Preparation and characterization of ultrafine electrospun polyacrylonitrile fibers and their subsequent pyrolysis to carbon fibers. Polym Int 55:825-833. doi:10.1002/pi.2040

Tang Z, Qiu C, McCutcheon JR et al (2009) Design and fabrication of electrospun polyethersulfone nanofibrous scaffold for high-flux nanofiltration membranes. J Polym Sci Part B: Polym Phys 47:2288-2300. doi:10.1002/polb.21831

Tripatanasuwan S, Zhong Z, Reneker DH (2007) Effect of evaporation and solidification of the charged jet in electrospinning of poly(ethylene oxide) aqueous solution. Polymer (Guildf) 48:5742-5746. doi:10.1016/j.polymer.2007.07.045

Van der Schueren L, De Schoenmaker B, Kalaoglu ÖI, De Clerck K (2011) An alternative solvent system for the steady state electrospinning of polycaprolactone. Eur Polym J 47:1256-1263. doi:10.1016/j.eurpolymj.2011.02.025

Varesano A, Carletto RA, Mazzuchetti G (2009) Experimental investigations on the multi-jet electrospinning process. J Mater Process Technol 209:5178-5185. doi:10.1016/j.jmatprotec.2009. 03.003

Xu Z-L, Alsalhy Qusay F (2004) Polyethersulfone (PES) hollow fiber ultrafiltration membranes prepared by $\mathrm{PES} /$ non-solvent/NMP solution. J Membr Sci 233:101-111. doi:10.1016/j.memsci.2004. 01.005

Yoon K, Hsiao BS, Chu B (2009) Formation of functional polyethersulfone electrospun membrane for water purification by mixed solvent and oxidation processes. Polymer (Guildf) 50:2893-2899. doi:10.1016/j.polymer.2009.04.047

Zuo W, Zhu M, Yang W et al (2005) Experimental study on relationship between jet instability and formation of beaded fibers during electrospinning. Polym Eng Sci 45:704-709. doi:10.1002/pen.20304 